Article

\title{
Strategies for Capital Constrained Timber and Carbon Sink Supply Chain under the Cap-and-Trade Scheme
}

\author{
Xinyue Yang, Ye Song *, Mingjun Sun and Hongjun Peng * \\ College of Economics and Management, Nanjing Forestry University, Nanjing 210037, China; \\ yxydtyxy@163.com (X.Y.); dejasunmj@126.com (M.S.) \\ * Correspondence: sonnieleaf@163.com (Y.S.); penghj@njfu.edu.cn (H.P.); \\ Tel.: +86-1377-639-0832 (Y.S.); Tel.: +86-1381-338-8466 (H.P.)
}

Received: 12 April 2020; Accepted: 22 May 2020; Published: 27 May 2020

\begin{abstract}
We consider a capital constrained timber and carbon sink supply chain under the cap-and-trade scheme, where the forest company produces timber and carbon sink. We consider two subsidy modes: financing subsidy to the carbon sink forests and financing subsidy to the manufacturer's emission reductions. We apply a Stackelberg model and mainly consider the impact of subsidies on the profits and the strategies of the supply chain members. The results show that when the government gives a financing subsidy to the carbon sink forests, it is conducive to promoting the expansion of carbon sink forests, as well as the enhancement of the forest company's profit. However, a larger supply of carbon sinks generates a lower price, which leads to the manufacturer reducing the technical emission reduction level and purchasing more carbon emission rights instead. On the other hand, when the manufacturer receives a financing subsidy for the technical emission reduction costs, its production becomes cleaner than before, and the profits of the forest company and the manufacturer increase.
\end{abstract}

Keywords: financing subsidy; supply chain; green finance; cleaner production

\section{Introduction}

Nowadays, global climate change is an indisputable fact that has caused many irreversible negative impacts on the global ecosystem and human society [1]. Climate change, especially global warming, is mainly caused by emissions of greenhouse gases from human production and companies' operating activities [1]. We should enhance capabilities to mitigate climate change. The key is to decrease the accumulation of greenhouse gases, which can be achieved in two ways: reducing the emissions of greenhouse gases (carbon sources) and increasing the absorption of greenhouse gases (carbon sinks).

The Kyoto Protocol has designed three flexible compliance mechanisms: Clean Development Mechanism (CDM), Joint Implementation (JI) and Emissions Trading (ET). Many studies have shown that forestry is an effective strategy to mitigate climate change. It can achieve carbon sequestration at a lower cost. In addition, the required technologies are mature, and effective carbon sequestration can be quickly carried out [2]. In addition to forestry, the wood product industry also plays a crucial role in reducing carbon emissions by increasing the biomass of live forests and the carbon stocks of wood products [3]. However, on the other hand, the energy consumption and material consumption of China's forestry industry are relatively high. The carbon intensity of intermediate processing products (such as plywood, fiberboard, etc.) and deep processing products (such as wood furniture, paper products, etc.) are relatively large [4].

Under the cap-and-trade policy, the timber and carbon sink supply chain has significant differences compared to the general one: the upstream forest company operates two different types of forests: 
timber forests and carbon sink forests, so the forest company can not only supply timber to the manufacturing company to produce wood forest products, but also sell forest carbon sinks in the carbon market. The downstream manufacturer of the timber and carbon sink supply chain faces a carbon cap and needs to invest in technical emission reductions. In view of the significant role of forestry in dealing with climate change and the particularity of the wood forest product supply chain, it is important to explore the green development of the wood forest products' supply chain.

On the one hand, the manufacturers with the task of reducing emissions need to carry out a technical emission reduction, which causes greater capital pressure and the corresponding financing needs. On the other hand, it is difficult and expensive for forest enterprises to finance themselves because of their long production cycle, slow capital recovery and high-risk level. Therefore, the popularity of environmental protection and cleaner production urges the emergence of green finance. To encourage technical investment in carbon emission reduction, carbon finance originated from the "Kyoto Protocol" in 1997. It is necessary to explore the influence of green finance on the profits and decisions of the wood forest product supply chain.

On the basis of the above analysis, we consider a two-level timber and carbon sink supply chain under the carbon cap-and-trade scheme. The supply chain consists of a capital constrained forest company and a capital constrained manufacturer. In order to urge the manufacturing company to achieve cleaner production, a certain subsidy is provided to the manufacturer's technology abatement costs. The forest company operates carbon sink forests and timber forests. Timber forests can be harvested regularly to supply wood and other raw materials to manufacturers. Carbon sink forests cannot be harvested. On the basis of meeting relevant transaction standards, forest carbon sinks are converted to carbon credits that can be traded in the carbon market. The forest carbon sinks generated by the carbon sink forests are able to enter the carbon market for trading after certified. The government grants a certain subsidy for the management cost of carbon sink forests under the green financing mechanism.

The structure of this paper is as follows. The related literature review and motivations are concluded in Section 2. The methods are explained in Section 3, and the results are analyzed in Section 4. We discuss the impact of some factors and present a numerical example in Section 5. The conclusions are stated in Section 6.

\section{Literature Review and Motivations}

\subsection{Forest Carbon Sinks}

Forests are estimated to absorb billions of tons of carbon dioxide globally each year, and if it is necessary to create comparable carbon sinks in other ways, it will require hundreds of billions of dollars in economic subsidies [5-7]. In addition, authors have shown that forest carbon trading can not only effectively increase the income of landowners from short-cycle plantations [8], but also promote climate change protection, thus providing economic, environmental, social and cultural benefits [5]. The significance of forest carbon sinks in coping with climate change has been widely recognized and incorporated into more climate policy frameworks [9].

The process of carbon sink management is vulnerable to a variety of natural disasters (fire, wind throw, drought, pathogen infestation, etc.) [10]. It can be solved in two ways: one is to design project-based offsets and payments under certain monitoring and verification criteria, and the other is to take uncertainty as risk discounting [11,12].

Through the above research, we can see that the importance of forest carbon sinks in the carbon market will become increasingly prominent. Therefore, based on the particularity of the wood forest product supply chain, it is extremely important to focus on exploring the impact of its financing behavior regarding the decision variables of the members within the supply chain under the green financing mechanism. 


\subsection{Green Financing Mechanism}

Green finance is an important force to promote green technology innovation in industries, and benefits SMEs through new intelligent green technologies [13-15]. Commercial banks have also recognized that there are many profit opportunities in the field of environmental protection finance [16-18]. At present, due to the existence of market failures, information gap, short-term behaviors, etc., the demand for green finance is strong while supply is insufficient, resulting in a huge financing gap [19]. To make up for this gap, some scholars have called on the government to make a difference and create a suitable financial ecosystem for the development of green enterprises by carrying out policy reforms $[20,21]$.

It can be seen that the existing research has carried out rich explorations of the form, source and optimization of green finance. However, there is no research applying green finance to the financing strategy of wood forest products' supply chain, or exploring the impacts of green finance on the supply chain members. We will focus on the above key points and explore whether green finance can promote carbon emission reduction and the growth of carbon sink forests.

\subsection{Low-Carbon Supply Chain Management}

In general, the expected level of profitability and social welfare of the centralized supply chain is significantly higher than that of the decentralized one, even when there is a carbon tax [22]. Moreover, it has been shown that, in the context of the carbon cap-and-trade policy, whether or not to consider carbon emission reduction inputs and trade credit financing provided by upstream suppliers depends on the downstream manufacturer's optimal financing strategy [23]. Yang et al. [24] find that the horizontal cooperation between two manufacturers would enhance carbon emission reduction rates and consumer welfare, while vertical cooperation between manufacturers and retailers could reduce wholesale prices, as well as increase the carbon reduction rate and achieve the optimization of the supply chain. To obtain a larger market share, the existence of green customers (whose sense of environmental protection is strong) will force companies to design more environmentally friendly supply chains to reduce unit carbon emissions $[25,26]$.

There may be conflicts of interest between members of the supply chain, and different types of contracts are required to enable them to cooperate to achieve supply chain coordination. Xu et al. [27] find that revenue-cost-sharing contracts are able to perfectly improve the performance of decentralized supply chains and enhance their input in carbon reduction without compromising the players' profits. Peng et al. [28] adopt a Stackelberg model and find that quantity discount contracts can be used to effectively improve the performance of the low-carbon supply chain, while revenue sharing contracts cannot. Sun et al. [4] design two different cost sharing mechanisms for the supply chain covered by the cap-and-trade policy. By solving the Stackelberg model, it turns out that both of them enable the supply chain to achieve higher profit levels.

Most of the studies about low-carbon supply chain management are centered on supply chain production decision-making and emission reduction decisions, while little attention is paid to low-carbon supply chain financing decisions. We will discuss the financing decisions of members within the timber and carbon sink supply chain under the carbon cap-and-trade policy.

\subsection{Motivation and Highlights}

This article considers a two-level supply chain of wood forest products consisting of forest enterprises and manufacturers. Among them, the manufacturers have the task of reducing emissions, which can be replaced by technology, purchasing carbon emission rights from the carbon market or forest carbon sinks from forest enterprises. The expected costs of production and technology for manufacturers all come from bank financing. To encourage manufacturers to reduce their emissions, banks give them a discount on financing for their technology costs. Forest enterprises operate carbon sink forests and timber forests. Timber forests can be harvested regularly to supply wood and other 
raw materials to manufacturers. Carbon sink forests cannot be harvested. In order to meet the relevant transaction standards, forest carbon sinks are converted to carbon credits that can be traded in the carbon market. All the cost of forest enterprises come from bank financing. To increase the enthusiasm of forest enterprises for operating carbon sink forests, banks give them certain financing discounts for carbon sink forest operating costs, when forest carbon sink financing mechanisms exist.

The innovations of this paper are the following: (1) In the context of carbon restrictions and trading policies, exploring green financing mechanisms to provide new ideas for solving the financing problems of forest enterprises, and providing a theoretical basis for the feasible implementation of low-carbon alternative policies; (2) Comparing the existence and lack of green financing mechanisms, the carbon strategic decisions of manufacturers in the supply chain of wood forest products, the decision on the scale of carbon sink forests by forest enterprises and the profits of both parties due to the existence of a carbon sink financing discount; (3) Through numerical analysis, discussing the impact of factors such as the loan interest rate, the low-carbon preference of consumers, the subsidy rate, etc., on the profit level of wood forest products' supply chain and the decision variables of each member of the supply chain. Finally, on this basis, summarizing the management inspirations.

\section{Methods}

In the timber and carbon sink supply chain we explore, there is a forest company that produces timber and forest carbon sinks, and a manufacturer who needs timber and carbon emission rights to produce wood forest products. A Stackelberg model is adopted to investigate the optimal production and carbon emission reduction decisions for the supply chain. In this paper, the manufacturer is the dominant party and decides first, while the forest company is the follower, who decides afterwards. The problem can be solved backward.

We have made some explanations on the notations we used in this paper in Table 1:

Table 1. List of notations.

\begin{tabular}{cl}
\hline Notation & \multicolumn{1}{c}{ Meaning } \\
\hline$a$ & the initial price of carbon emission rights in the carbon market \\
$b_{1}$ & the coefficient used to indicate the impact of the carbon cap on the price of emission rights \\
$b_{2}$ & the coefficient used to indicate the impact of carbon sink forests' scale on the price of \\
$c_{1}$ & emission rights \\
$c_{2}$ & unit cost of managing timber forests, $p_{s}>c_{1}(1+r)$ \\
$c_{t}$ & technical emission reduction cost of the manufacturer's unit \\
$D_{0}$ & consumers' basic demand for products produced by the manufacturer \\
$D$ & consumers' demand for products produced by the manufacturer \\
$e$ & the initial carbon emission of each unit product \\
$\Delta e$ & the emission reduction of each unit product, which is decided by the manufacturer \\
$G$ & the carbon cap of the manufacturer \\
$p_{m}$ & unit price for the products produced by the manufacturer \\
$p_{s}$ & unit price for timber \\
$p_{t}$ & unit price for the forest carbon sink (which equals the price of the carbon emission rights) \\
$q_{c}$ & the scale of carbon sink forests \\
$r$ & market interest rates \\
$u_{1}$ & the sensitivity coefficient of customers' demand to the emission reduction level \\
$u_{2}$ & the sensitivity coefficient of customers' demand to the scale of carbon sink forests \\
$\varepsilon$ & the amount of carbon that can be sequestrated per unit of carbon sink forest \\
$\theta_{1}$ & interest rate subsidy for the forest company's carbon sink forest management costs \\
$\theta_{2}$ & interest rate subsidy available for the manufacturer's emission reduction costs \\
$\pi_{m}$ & profit of the manufacturer \\
$\pi_{s}$ & profit of the forest company
\end{tabular}


For the purpose of making the model more realistic, the following assumptions are made, which distinguish our research from that of other scholars.

Assumption 1. Assuming that there is a low-carbon preference in the market, the sales volume of finished products is an increasing function of the unit emission reduction amount $(\Delta e)$ and the scale of the carbon sink forests of the upstream supplier $\left(q_{c}\right)$.

Considering high carbon emissions from the manufacturing process and the important role of forestry in offsetting carbon emissions, when choosing wood forest products, consumers will not only pay attention to the technical emission reductions of manufacturing companies, but also to the scale of carbon sink forests managed by forest companies within the supply chain. So, the consumers' demand for finished products can be expressed as [26]:

$$
D=D_{0}+u_{1} \Delta e+u_{2} q_{c}
$$

where $u_{1}$ and $u_{2}$ reflect the low-carbon awareness of consumers. Specifically, $u_{1}$ indicates the sensitivity coefficient of consumer demand to the carbon emission reduction of the manufacturer, while $u_{2}$ indicates the sensitivity coefficient of consumer demand to the scale of carbon sink forests managed by upstream forest companies. Based on an actual situation, the additional market demand on account of low-carbon preference is limited, so we assume that:

$$
D_{0}>u_{1} \Delta e+u_{2} q_{c}
$$

Assumption 2. To make the model simpler, we assume that the amount of timber forests exactly meets the order of the manufacturing company, and the remaining forests are carbon sink forests. In addition, the forest company needs to spend more money and efforts managing carbon sink forests, so $c_{1}<c_{2}$.

Assumption 3. We take the price of forest carbon sinks negatively correlated to the carbon cap and the scale of carbon sink forests. It can be expressed as follows:

$$
p_{t}=a-b_{1} G-b_{2} \varepsilon q_{c}, a>0, b_{i}>0
$$

wherea is the initial price of carbon emission rights in the carbon market, $b_{1}$ is the coefficient used to indicate the impact of the carbon cap on the price of emission rights, $a{ }^{2} b_{2}$ is the coefficient used to indicate the impact of the carbon sink forests' scale on the price of emission rights.

The value of the carbon cap reflects the severity of the carbon restraint policy. The smaller the carbon cap, the stricter the carbon restraint policy, and thus the greater the demand for carbon emission rights by the companies subject to the carbon policy, according to the law of supply and demand, the higher the market price of the carbon sinks. The main role of forest carbon sinks is to offset carbon emissions, so it is essentially the same as that of carbon emission rights. Therefore, we assume that the price of forest carbon sinks equals that of carbon emission rights.

Assumption 4. Assuming that the carbon emission reduction cost is a quadratic function related to the manufacturer's emission reduction level:

$$
C(\Delta e)=\frac{1}{2} c_{t}(\Delta e)^{2}
$$

As Ji et al. [26], we assume that the value of $c_{t}$ is relatively large.

\section{Results}

The capital constrained timber and carbon sink supply chain under the green financing mechanism is showed in Figure 1. We can see that the manufacturer's capital is made up of two parts: one is the 
raw material ordering cost, the other is the technical emission reduction cost. The money that the forest company needs to borrow also consists of two parts: one part is the timber forests' management cost, the other part is the carbon sink forests' management cost. According to our field of research, the cost of purchasing raw materials accounts for an important part of the manufacturing costs of wood forest products companies. Moreover, with the implementation of the carbon cap policy, in order to achieve clean production, the investment in technical emission reduction measures such as equipment update is very high. Therefore, we mainly focus on these two costs. On the other hand, the forest company's costs for managing timber forests include afforestation costs, maintenance costs, infrastructure costs, etc. In addition, the management of carbon sink forests requires additional information search costs, negotiation costs, monitoring costs, etc.

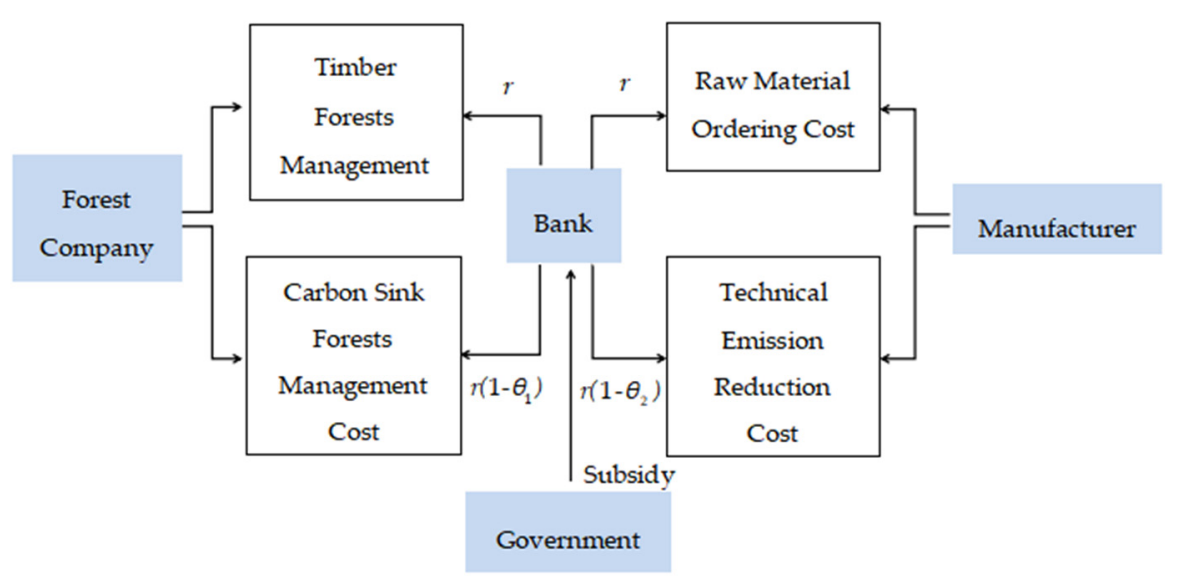

Figure 1. The capital constrained timber and carbon sink supply chain.

In general, we assume that the capitals of the forest company and the manufacturer are all from the bank loans. For the purpose of supporting the forest company in managing the carbon sink forests, there is a subsidy $\left(\theta_{1}\right)$ for the carbon sink forests' management cost, and the government as well as the bank encourage the manufacturer to take measures to reduce carbon emissions. The government provides a certain subsidy $\left(\theta_{2}\right)$ for the technical emission reduction cost.

Under the green financing mechanism, the forest company's profit can be expressed as:

$$
\pi_{s}\left(q_{c}\right)=p_{s} q_{m}+\left(a-b_{1} G-b_{2} \varepsilon q_{c}\right) \varepsilon q_{c}-\left\{c_{1} q_{m}(1+r)+c_{2} q_{c}\left[1+\left(1-\theta_{1}\right) r\right]\right\}
$$

It consists of three parts: the first part is the income from selling timber, the second is the carbon sink sales revenue and the third is the total cost of managing different forests and financing costs. $c_{2} q_{c}\left[1+\left(1-\theta_{1}\right) r\right]$ refers to the sum of the management costs and financing costs incurred by the forest company in managing the carbon sink forests under the green financing mechanism.

In the game model, the manufacturer is the leader who decides first and the forest company is the follower who decides later. We solve the model backward.

We take the condition of the forest company's profit maximization into consideration and obtain the optimal decision of the forest company $q_{c}$ as follows:

Proposition 1. Under the green financing mechanism, the optimal scale of carbon sink forests is given by:

$$
q_{c}^{*}=\frac{A-B}{2 b_{2} \varepsilon^{2}}
$$

where $A=\left[p_{s}-c_{1}(1+r)\right] u_{2}+\left(a-b_{1} G\right) \varepsilon, B=c_{2}\left[1+\left(1-\theta_{1}\right) r\right]$.

(The proof of Proposition 1 is in Appendix A.1) 
Proposition 1 indicates that factors such as carbon sink loan subsidy, interest rate, carbon cap and unit cost of managing carbon sink forests will affect the forest company's optimal production scale of carbon sink forests.

Under the green financing mechanism, the profit of the manufacturer is as follows:

$$
\pi_{m}(\Delta e)=\left[p_{m}-p_{s}(1+r)\right] q_{m}-\left(a-b_{1} G-b_{2} \varepsilon q_{c}\right)\left[q_{m}(e-\Delta e)-G\right]-\frac{1}{2} c_{t}(\Delta e)^{2}\left[1+\left(1-\theta_{2}\right) r\right]
$$

where the first part is the gross income of wood forest products, the second is the income/cost at which the manufacturing company sells/purchases carbon emission rights from the carbon market and the third is the sum of the technical emission reduction costs and financing costs.

On the basis of the forest company's decision about the scale of carbon sink forests, the carbon cap and the price of carbon emission rights, the manufacturing company decides its emission reduction level. Thus, the manufacturer's decision model is as follows:

$$
\max \pi_{m}(\Delta e) \text { s.t. }(2)
$$

Proposition 2. Under the green financing mechanism, the manufacturer's optimal emission reduction level is:

$$
\Delta e^{*}=\frac{u_{1}\left[p_{m}-p_{s}(1+r)\right]+p_{t}\left(D_{0}-e u_{1}+u_{2} q_{c}^{*}\right)}{C-2 u_{1} p_{t}}
$$

whereC $=c_{t}\left[1+\left(1-\theta_{2}\right) r\right], p_{t}=a-b_{1} G-b_{2} \varepsilon q_{c}$.

(The proof of Proposition 2 is in Appendix A.2)

Proposition 2 indicates that factors such as the technical emission reduction financing subsidy, interest rate, technical emission reduction cost coefficient, carbon cap will cause differences in the manufacturing company's emission reduction amount of unit product.

\section{Discussions}

In this section, we will discuss how the parameters affect the optimal decisions and profits of the wood forest product supply chain. Meanwhile, we consider some numerical examples to gain further insights. In particular, we combine the real case of the timber and carbon sink supply chain and related data we have put together and then set up the parameters in Table 2.

Table 2. The values of the parameters.

\begin{tabular}{cccccccccc}
\hline Parameters & $a$ & $b_{1}$ & $b_{2}$ & $c_{1}$ & $c_{2}$ & $c_{t}$ & $D$ & $e$ & \\
\hline Values & $100 \mathrm{CNY}$ & 0.02 & 0.005 & $25 \mathrm{CNY}$ & $30 \mathrm{CNY}$ & $18,000 \mathrm{CNY}$ & 1000 & $3 \mathrm{tCO}_{2}$ \\
\hline Parameters & $G$ & $p_{m}$ & $p_{s}$ & $r$ & $u_{1}$ & $u_{2}$ & $\varepsilon$ & $\theta_{1}$ & $\theta_{2}$ \\
\hline Values & $2800 \mathrm{tCO}_{2}$ & $90 \mathrm{CNY}$ & $60 \mathrm{CNY}$ & 0.04 & 5 & 0.05 & 0.8 & 0.5 & 0.3 \\
\hline
\end{tabular}

\subsection{Impact of Subsidy Rates}

Proposition 3. (1) $\frac{d q_{c}^{*}}{d \theta_{1}}>0 ; \frac{d \pi_{s}}{d \theta_{1}}>0 ;(2) \frac{d \Delta e^{*}}{d \theta_{2}}>0 ; \frac{d \pi_{s}}{d \theta_{2}}>0 ; \frac{d \pi_{m}}{d \theta_{2}}>0$.

(The proof of Proposition 3 is in Appendix A.3)

Proposition 3 indicates that the existence of a subsidy for the forest carbon sink cost will urge the forest company to expand the production scale of carbon sink forests. Accordingly, the profit of the forest company will increase. The management rationale is the following: since forest carbon sinks are conducive to the improvement of the local ecological environment and have obvious positive 
externality, the government can subsidize the financing interest for the forest company's costs of managing carbon sink forests.

Proposition 3 also shows that giving a certain subsidy for the loans that the manufacturing company borrowed for technical emission reduction can enhance its carbon emission reduction level, which is beneficial to its cleaner production. The management rationale is the following: under the policy of carbon cap-and-trade, to encourage the manufacturer to reduce carbon emissions, the government can provide appropriate subsidies for the financing interest of the manufacturer's costs generated by technical reduction.

According to Proposition 3, when the government raises the subsidy for the manufacturer's technical emission reduction cost, both the profits of the forest company and the manufacturer increase. This is because a higher emission reduction level will result in a higher demand for the finished products, which encourages the manufacturer to increase its timber order. As a result, both the forest company and the manufacturer's revenue increase.

As can be seen in Figure 2, the emission reduction level of the manufacturer becomes lower when the subsidy for the carbon sink forests' management costs increases. This is because when the subsidy for the carbon sink cost increases, a larger carbon sink supply will cause a lower price, and the manufacturer will prefer purchasing the forest carbon credit rather than adopting technical emission reductions. The managerial insight of Figure 3 is that when there is a subsidy for forest carbon sink costs, for the purpose of encouraging the manufacturer to reduce carbon emissions, the government can maintain a reasonable carbon price by cutting down the carbon cap.

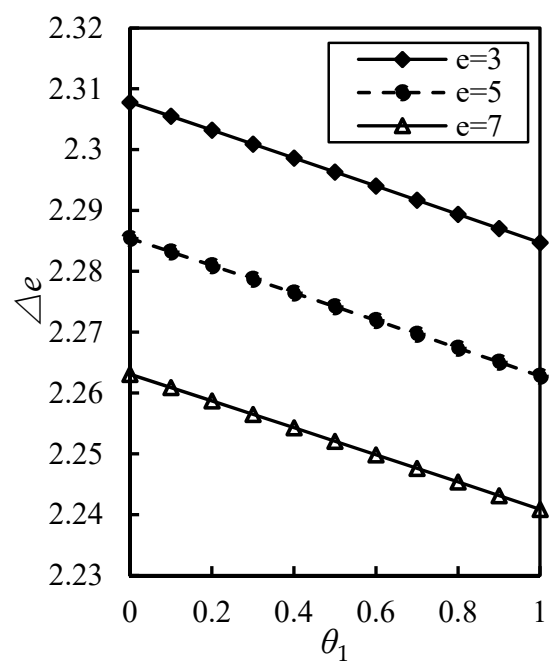

Figure 2. Unit amount of emission reduction vs. $\theta_{1}$.
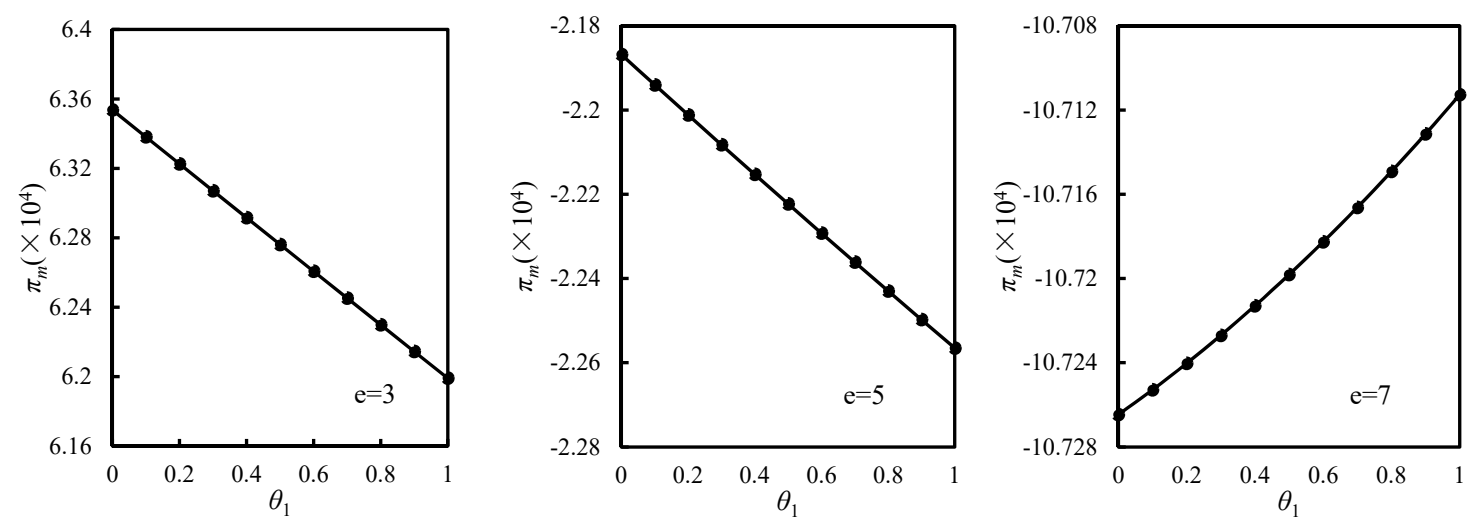

Figure 3. Profit of the manufacturer with different initial emissions vs. $\theta_{1}$. 
As shown in Figure 3, when the level of the manufacturing company's initial carbon emission is low $(e=3,5)$, its profit decreases with the increase of $\theta_{1}$. However, when the level of the manufacturing company's initial carbon emission is high $(e=7)$, its profit (loss) will increase (decrease) with $\theta_{1}$. According to the theory of demand and supply and Proposition 3, the increase in carbon sink supply will cause the price of carbon sinks to fall. The cleaner manufacturer with low initial carbon emissions may sell carbon credits in the carbon trading market. Thus, a lower carbon price will result in a lower carbon credit income. On the other hand, the manufacturer with high initial carbon emissions still cannot meet the requirements of low-carbon production and needs to purchase carbon emission rights from the market. Obviously, a lower carbon price is beneficial to the manufacturer with high initial carbon emissions.

\subsection{Impact of Consumers' Sensitivity}

Proposition 4. (1) $\frac{d \Delta e^{*}}{d u_{1}}>0 ; \frac{d \pi_{s}}{d u_{1}}>0 ;(2) \frac{d q_{c}^{*}}{d u_{2}}>0$.

(The proof of Proposition 4 is in Appendix A.4)

It can be seen from Proposition 4 that as consumers' sensitivity coefficient to the carbon emission reduction increases, in order to achieve cleaner production and attract more consumers, the manufacturer will put more effort into technical emission reduction. From (1), we can also see that consumers' sensitivity coefficient to the carbon emission reduction does not affect the decision of carbon sink forests for the forest company.

Proposition 4 also shows that customers' low-carbon preference is beneficial to the forest company. This is because when consumers' low-carbon preference increases, the manufacturer will invest more to increase the carbon emission reduction level, which will expand the demand of products. Under this condition, the order of timber by the manufacturer increases, which benefits the forest company.

We can conclude from Proposition 4 that consumers' sensitivity coefficient to the scale of carbon sink forests has a positive impact on the forest company, that is, the scale of carbon sink forests will be expanded with the increase of the sensitivity coefficient.

Figure 4 shows that when the initial carbon emission levels are different, as $u_{1}$ increases, the manufacturing company's profit shows different trends. When $e$ is relatively low $(e=2.5)$, the manufacturer is relatively clean, and its profit increases with $u_{1}$. However, when $e$ is relatively large $(e=3.5)$, the manufacturer's profit decreases with $u_{1}$. For manufacturers with high carbon emissions, a greater market demand means greater carbon emissions, and the emission reduction is more difficult. They have to invest more in technical emission reduction and purchase more carbon credit as well. As a result, their increased sales revenue may be less than the costs of emission reduction, which leads to declining income. When $e=3$, as $u_{1}$ increases, the profit of the manufacturing company decreases first, then increases. This is because both market demand and carbon emissions will increase with $u_{1}$, and the manufacturer needs to spend more on emission reduction. When $u_{1}$ is relatively small, the increased sales revenue of the manufacturer is less than the costs of additional emission reductions. As $u_{1}$ increases, the additional sales revenue continues to increase until it is greater than the costs of emission reduction, and the profit level gradually rises.

Figures 5 and 6 show that when the consumers' sensitivity coefficient to the scale of carbon sink forests is high, low-carbon demand guides production and reduction actions. So, in order to achieve cleaner production and win more market share, the manufacturer will invest more in carbon reduction technology, thus reducing the unit carbon intensity of finished products. Moreover, the manufacturer's needs for forest carbon sinks will increase, which promotes the expansion of carbon sink forests and improves the profitability of the forest company. 

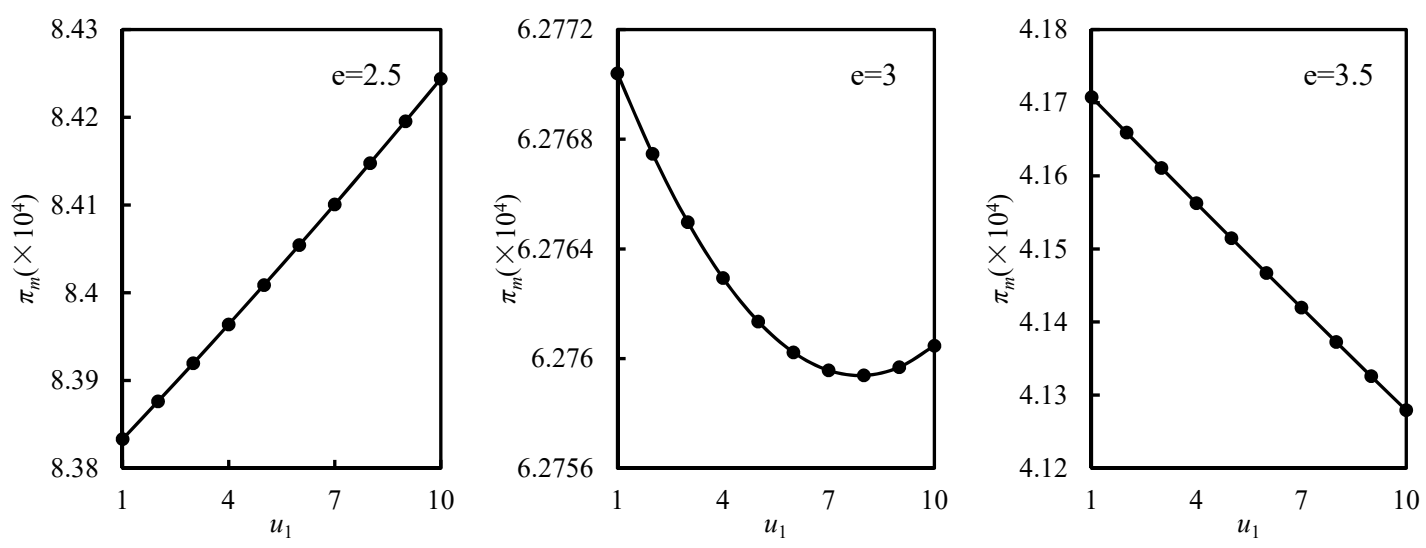

Figure 4. Profit of the manufacturer vs. $u_{1}$.

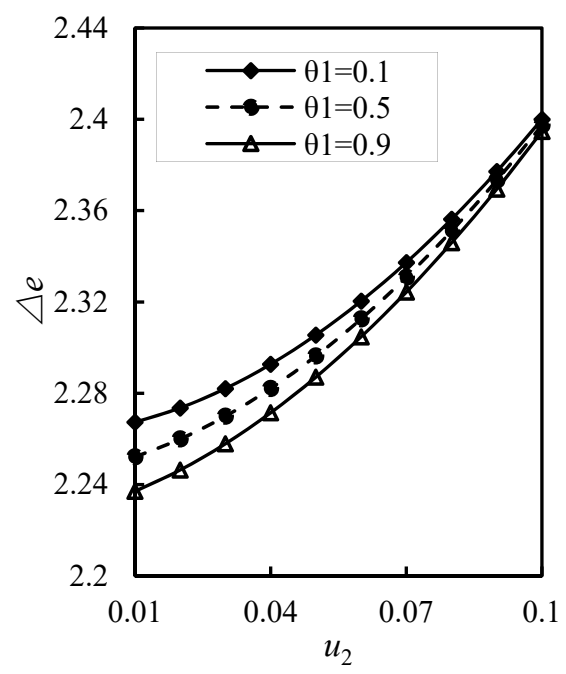

Figure 5. Unit carbon emission reductions vs. $u_{2}$.

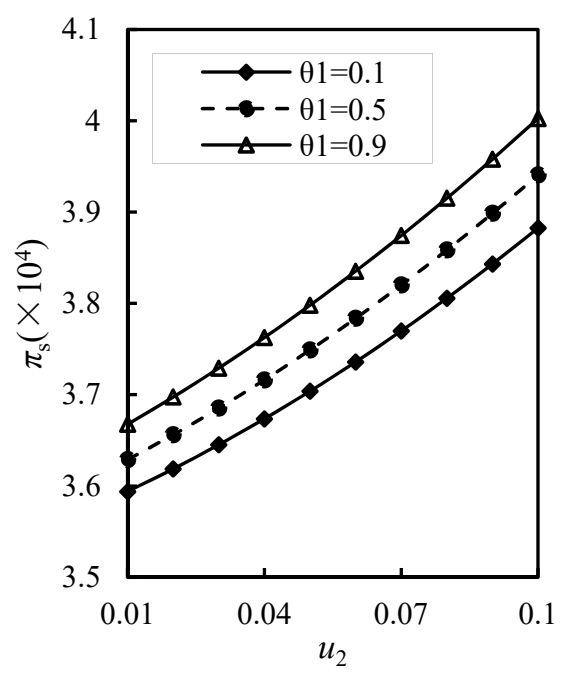

Figure 6. Profit of the forest company vs. $u_{2}$.

The management rationale of Proposition 4 and Figures 5 and 6 is the following: the government is supposed to intensify the low-carbon publicity campaign, advocate the concept of low-carbon life and effectively improve the low-carbon preference of society by establishing a green labeling mechanism. As a result, the needs for emission rights and forest carbon sinks increase, which leads to the expansion 
of carbon sink forests and a greater supply of forest carbon sinks, hence achieving a virtuous cycle in the carbon market itself.

As shown in Figure 7, when the initial unit carbon emissions are different, as $u_{2}$ increases, the profits of the manufacturer decrease. When $e$ is relatively small $(e=2.5,3)$, the manufacturer with low initial carbon emissions can sell its remaining emission rights. However, as the consumers' preference for the scale of carbon sink forests increases, the market demand increases as well, while the price of carbon emission right $\left(p_{t}\right)$ decreases. Moreover, the increase in the sales revenue of finished products is less than the decrease in the sales revenue of remaining carbon emission rights, and thus the income decreases. When $e$ is relatively large $(e=3.5)$, the initial carbon dioxide of the manufacturing company is discharge initially is large. What is worse, more demand leads to more emissions, and the manufacturer has to spend more on emission reductions. As a result, the manufacturer's profit level falls more sharply. Therefore, for the purpose of striving to maximize profits, the manufacturing company should properly weigh the emission reduction input in relation to the market share, and avoid being blindly guided by market demand.
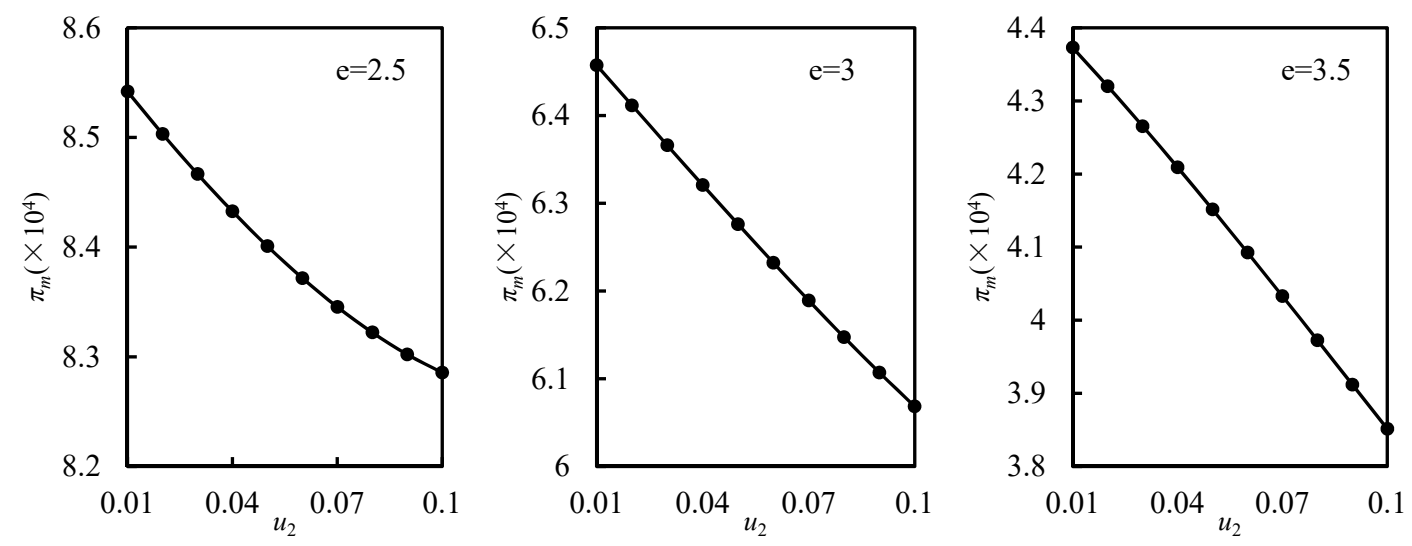

Figure 7. Profit of the manufacturer vs. $u_{2}$.

\subsection{Impact of Carbon Cap}

Proposition 5. (1) $\frac{d q_{c}^{*}}{d G}<0 ;(2) \frac{d \Delta e^{*}}{d G}<0$.

(The proof of Proposition 5 is in Appendix A.5)

According to Proposition 5, it is easy to see that the larger the carbon cap, the looser the emission policy; that the smaller the manufacturer's pressure for reducing carbon emissions, the lower the demand for carbon credits; and that the lower the reduction amount of the manufacturing company, the smaller the scale of carbon sink forests. The management implication is that for truly achieving the implementation effect of the carbon-reduction policies, and thus promoting the green development of the supply chain and the overall economy, the carbon cap should be properly tightened.

\section{Conclusions}

We take the two-level wood forest product supply chain consisting of a single manufacturer and a single forest company as the research object. The upstream forest company manages carbon sink forests and timber forests. The wood harvested from timber forests provides raw materials for the downstream manufacturer, while the forest carbon sink generated from the carbon sink forests is certified to enter the carbon market. Under the carbon cap-and-trade policy, we focused on the impact of the green financing mechanism on the supply chain profit and the decision variables of 
each member. Then, we discussed the feasibility of alleviating the financing pressure of the forest company and implementing an emission reduction policy through the green financing mechanism, bed on the construction of a Stackelberg game model. The research shows that under the green financing mechanism, the existence of a carbon sink forest financing discount is conducive to promoting the expansion of carbon sink forests and the profit level of the forest company. However, this discount has a negative impact on the unit carbon emission reduction level and the profit of the cleaner manufacturer, as a larger supply of carbon sinks results in a lower price. The relatively clean manufacturer reduces the technical emission reduction investment and purchases more carbon emission rights instead, which leads to a decline of the remaining carbon credits available for sale and to a reduction in income. On the other hand, the existence of a technical emission reduction financing discount can improve not only the unit carbon emission reduction level and the profit level of the manufacturer, but also the profitability of the forest company, thus guaranteeing the smooth implementation of the emission reduction policy. The rationale is that the government can solve the cost problem of the forest company through the green financing mechanism, and can also increase carbon emission reduction by granting subsidies to the manufacturer.

In addition, the scale of carbon sink forests is negatively correlated with the interest rate and the carbon limit, and positively correlated with the consumers' sensitivity coefficient to the scale of carbon sink forests. The unit carbon emission reduction of the manufacturer is negatively correlated with the interest rate, the technical emission reduction cost coefficient and the carbon limit, while positively correlated with the technical emission reduction financing discount.

The conclusions of this paper show that the existence of a technical emission reduction financing discount can improve not only the unit carbon emission reduction level and the profit level of the manufacturer, but also the profitability of the forest company, which provides a certain direction for future research. In future research, we can focus on the optimal level of technical emission reduction financing discounts, so as to provide a theoretical basis for the government to formulate policies.

Author Contributions: H.P. set up the framework of this paper; X.Y. collected the data and examples and wrote the first draft of the paper; Y.S. did the calculations of the models and analyzed the data; M.S. designed the financing mechanism. All authors have read and agreed to the published version of the manuscript.

Funding: This research was funded by the National Social Science Foundation of China (grant no. 17BGL236).

Acknowledgments: During the numerical study, the Nanjing Forestry Bureau provided us with relevant data, which was very helpful.

Conflicts of Interest: The authors declare no conflict of interest. The funders had no role in the design of the study; in the collection, analyses, or interpretation of data; in the writing of the manuscript, or in the decision to publish the results.

\section{Appendix A}

Appendix A.1. Proof of Proposition 1

From (1), we can get that

$$
\begin{gathered}
\frac{d \pi_{s}}{d q_{c}}=u_{2} p_{s}-u_{2} c_{1}(1+r)+\left(a-b_{1} G\right) \varepsilon-2 b_{2} \varepsilon^{2} q_{c}-c_{2}\left[1+\left(1-\theta_{1}\right) r\right] \\
\frac{d^{2} \pi_{s}}{d q_{c}{ }^{*}}=-2 b_{2} \varepsilon^{2}<0
\end{gathered}
$$

So, $\pi_{s}$ is a concave function of $q_{c}$. Let $d \pi_{s} / d q_{c}=0$, and we can derive (2). 
Appendix A.2. Proof of Proposition 2

From (3), (4) and Assumption 4, we can derive that

$$
\begin{gathered}
\frac{d \pi_{m}}{d \Delta e}=\left[p_{m}-p_{s}(1+r)\right] u_{1}+p_{t}\left(D_{0}-e u_{1}+u_{2} q_{c}\right)+\left\{2 p_{t} u_{1}-c_{t}\left[1+\left(1-\theta_{2}\right) r\right]\right\} \Delta e \\
\frac{d^{2} \pi_{m}}{d \Delta e^{2}}=2 p_{t} u_{1}-c_{t}\left[1+\left(1-\theta_{2}\right) r\right]<0
\end{gathered}
$$

On the basis of Assumption 4, the value of $c_{t}$ is relatively large, so $c_{t}>\frac{2 p_{t} u_{1}}{1+\left(1-\theta_{2}\right) r}$. Thus $\frac{d^{2} \pi_{m}}{d \Delta e^{2}}<0$ and $\pi_{m}(\Delta e)$ is a concave function of $\Delta e$. Let $\frac{d \pi_{m}}{d \Delta e}=0$, and we can derive (5).

Appendix A.3. Proof of Proposition 3

From (2), it is obvious that

$$
\frac{d q_{c}^{*}}{d \theta_{1}}=\frac{c_{2} r}{2 b_{2} \varepsilon}>0
$$

From (1), we can get that

$$
\frac{d \Delta e^{*}}{d \theta_{2}}=\frac{c_{t} r\left\{u_{1}\left[p_{m}-p_{s}(1+r)\right]+p_{t}\left(D_{0}-e u_{1}\right)\right\}}{\left(C-2 u_{1} p_{t}\right)^{2}}+\frac{c_{t} r u_{2} p_{t}(A-B)}{2 b_{2} \varepsilon^{2}\left(C-2 u_{1} p_{t}\right)^{2}}
$$

$p_{m}-p_{s}(1+r)$ is the manufacturer's gross income of finished products, so $p_{m}-p_{s}(1+r)>0$. Since $q_{c}^{*}=\frac{A-B}{2 b_{2} \varepsilon^{2}}>0$, we get that $A>B$. From Assumption 2, we can get that $D_{0}>u_{1}$ e. So $\frac{d \Delta e^{*}}{d \theta_{2}}>0$.

From (3), we can get that

$$
\frac{d \pi_{m}^{*}}{d \theta_{2}}=\frac{\partial \pi_{m}^{*}}{\partial \Delta e^{*}} \cdot \frac{d \Delta e^{*}}{\partial \theta_{2}}+\frac{\partial \pi_{m}^{*}}{\partial \theta_{2}}=\frac{1}{2} c_{t} r\left(\Delta e^{*}\right)^{2}>0
$$

Appendix A.4. Proof of Proposition 4

From (5), we can derive that

$$
\Delta e^{*}=\frac{2 u_{1}\left[p_{m}-p_{s}(1+r)\right]+2 p_{t} D_{0}-e C}{2\left(C-2 u_{1} p_{t}\right)}+\frac{u_{2} p_{t}(A-B)}{2 b_{2} \varepsilon^{2}\left(C-2 u_{1} p_{t}\right)}+\frac{e}{2}
$$

So, we can get that $d \Delta e^{*} / d u_{1}>0$. Further, since

$$
D=D_{0}+u_{1} \Delta e+u_{2} q_{c}, d D / d u_{1}=\Delta e^{*}+u_{1}\left(d \Delta e^{*} / d u_{1}\right)>0
$$

So, from (1), we can get that

$$
\frac{d \pi_{s}^{*}}{d u_{1}}=\left[p_{s}-c_{1}(1+r)\right]\left(d D / d u_{1}\right)>0
$$

From (2), we can derive that $\frac{d q_{c}^{*}}{d u_{2}}=\frac{p_{s}-c_{1}(1+r)}{2 b_{2} \varepsilon^{2}}, p_{s}-c_{1}(1+r)$ is the gross income from selling timber, so $p_{s}-c_{1}(1+r)>0$, and thus $d q_{c}^{*} / d u_{2}>0$.

Appendix A.5. Proof of Proposition 5

From (2) and (5), we can derive that

$$
\frac{d q_{c}^{*}}{d G}=-\frac{b_{1}}{2 b_{2} \varepsilon}<0
$$




$$
\frac{d \Delta e^{*}}{d G}=-\frac{b_{1} C\left(D_{0}-e u_{1}\right)-2 b_{1} u_{1}^{2}\left[p_{m}-p_{s}(1+r)\right]}{2\left(C-2 u_{1} p_{t}\right)^{2}}-\frac{b_{1} u_{2} p_{t}(A-B)\left(1+2 u_{1} p_{t}\right)}{4 b_{2} \varepsilon^{2}\left(C-2 u_{1} p_{t}\right)}-\frac{b_{1} u_{2} p_{t}}{2 b_{2} \varepsilon\left(C-2 u_{1} p_{t}\right)}<0
$$

\section{References}

1. He, Z.X.; Shen, W.X.; Li, Q.B.; Xu, S.C.; Zhao, B.; Long, R.Y.; Chen, H. Investigating external and internal pressures on corporate environmental behavior in papermaking enterprises of China. J. Clean. Prod. 2018, 172, 1193-1211. [CrossRef]

2. Zheng, C.C.; Zhang, Y.; Cheng, D.X. Forest Carbon Sink: A Potential Forest Investment. AIP Conf. Proc. 2017, 1794, 1-4.

3. Knauf, M. A multi-tiered approach for assessing the forestry and wood products industries' impact on the carbon balance. Carbon Balance Manag. 2015, 10, 1-11. [CrossRef] [PubMed]

4. Sun, M.J.; Peng, H.J.; Wang, S. Cost-Sharing Mechanisms for A Wood Forest Product Supply Chain under Carbon Cap-and-Trade. Sustainability 2018, 10, 4345. [CrossRef]

5. Canadell, J.G.; Raupach, M.R. Managing Forests for Climate Change Mitigation. Science 2008, 320, $1456-1457$. [CrossRef]

6. Vass, M.M.; Elofsson, K. Is forest carbon sequestration at the expense of bioenergy and forest products cost-efficient in EU climate policy to 2050? J. Forest Econ. 2016, 24, 82-105. [CrossRef]

7. Michetti, M.; Rosa, R. Afforestation and timber management compliance strategies in climate policy. A computable general equilibrium analysis. Ecol. Econ. 2012, 77, 139-148. [CrossRef]

8. Zhou, W.; Gao, L. The impact of carbon trade on the management of short-rotation forest plantations. Forest Policy Econ. 2016, 62, 30-35. [CrossRef]

9. Nabuurs, G.J.; Delacote, P.; Ellison, D.; Hanewinkel, M.; Hetemaki, L.; Lindner, M. By 2050 the mitigation effects of EU forests could nearly double through climate smart forestry. Forest 2017, 8, 484. [CrossRef]

10. Williams, C.A.; Gu, H.; MacLean, R.; Masek, J.G.; Collatz, G.J. Disturbance and the carbon balance of US forests: A quantitative review of impacts from harvests, fires, insects, and droughts. Glob. Planet. Chang. 2016, 143, 66-80. [CrossRef]

11. Gren, I.M.; Aklilu, A.Z. Policy design for forest carbon sequestration: A review of the literature. Forest Policy Econ. 2016, 70, 128-136. [CrossRef]

12. Knoke, T. Mixed forests and finance-Methodological approaches. Ecol. Econ. 2008, 65, 590-601. [CrossRef]

13. Li, K.F.; Liu, C.Z. Construction of Carbon Finance System and Promotion of Environmental Finance Innovation in China. Energy Procedia 2011, 5, 1065-1072.

14. Mahbouli, H.; Fortes, D. Is green microfinance 'investment ready'? Perspective of an international impact investor. Enterp. Dev. Microfinanc. 2015, 26, 222-229. [CrossRef]

15. Jin, J.Y.; Han, L.Y. Assessment of Chinese green funds: Performance and industry allocation. J. Clean. Prod. 2018, 171, 1084-1093. [CrossRef]

16. Soundarrajan, P.; Vivek, N. Green finance for sustainable green economic growth in India. Agric. Econ. 2016, 1, 35-44. [CrossRef]

17. Xu, D.W.; Zhao, P. Establishing and Analyzing Commercial Banks' Carbon Finance Business Revenue Model. Int. Manag. Rev. 2018, 14, 42-47.

18. Zhu, W.Z.; Zhu, Z.G.; Fang, S.Q.; Pan, W.T. Chinese Students' Awareness of Relationship between Green Finance, Environmental Protection Education and Real Situation. Eurasia J. Math. Sci. Technol. Edu. 2017, 13, 3753-3769. [CrossRef]

19. Clark, R.; Reed, J.; Sunderland, T. Bridging funding gaps for climate and sustainable development: Pitfalls, progress and potential of private finance. Land Use Policy 2018, 71, 335-346. [CrossRef]

20. Owen, R.; Brennan, G.; Lyon, F. Enabling investment for the transition to a low carbon economy: Government policy to finance early stage green innovation. Curr. Opin. Environ. Sustain. 2018, 31, 137-145. [CrossRef]

21. Cui, L.B.; Huang, Y.R. Exploring the Schemes for Green Climate Fund Financing: International Lessons. World Dev. 2018, 31, 137-145. [CrossRef]

22. Wang, C.X.; Wang, W.; Huang, R.B. Supply chain enterprise operations and government carbon tax decisions considering carbon emissions. J. Clean. Prod. 2017, 152, 271-280. [CrossRef]

23. Cao, E.B.; Du, L.X.; Ruan, J.H. Financing preferences and performance for an emission-dependent supply chain: Supplier vs. bank. Int. J. Prod. Econ. 2019, 208, 383-399. [CrossRef] 
24. Yang, L.; Zhang, Q.; Ji, J. Pricing and carbon emission reduction decisions in supply chains with vertical and horizontal cooperation. Int. J. Prod. Econ. 2017, 191, 286-297. [CrossRef]

25. Nouira, I.; Hammami, R.; Frein, Y.; Temponi, C. Design of forward supply chains: Impact of a carbon emissions-sensitive demand. Int. J. Prod. Econ. 2016, 173, 80-98. [CrossRef]

26. Ji, J.N.; Zhang, Z.Y.; Yang, L. Carbon emission reduction decisions in the retail-/dual-channel supply chain with consumers' preference. J. Clean. Prod. 2017, 141, 852-867.

27. Xu, L.; Wang, C.; Li, H. Decision and coordination of low-carbon supply chain considering technological spillover and environmental awareness. Sci. Rep. 2017, 7, 3107. [CrossRef]

28. Peng, H.J.; Pang, T.; Cong, J. Coordination contracts for a supply chain with yield uncertainty and low-carbon preference. J. Clean. Prod. 2018, 205, 291-302. [CrossRef]

(C) 2020 by the authors. Licensee MDPI, Basel, Switzerland. This article is an open access article distributed under the terms and conditions of the Creative Commons Attribution (CC BY) license (http://creativecommons.org/licenses/by/4.0/). 